\title{
Effect-site concentration of remifentanil for blunting hemodynamic responses to tracheal intubation using light wand during target controlled infusion-total intravenous anesthesia
}

\author{
Jun Heum Yon, Jae Keun Jo, Young-Suk Kwon, Hae-Gyun Park, and Sangseok Lee \\ Department of Anesthesiology and Pain Medicine, Sanggye Paik Hospital, College of Medicine, Inje University, Seoul, Korea
}

Background: Transillumination using a light wand is an alternative type of laryngoscope used for tracheal intubation. There is little information available on the effect-site concentration of remifentanil required to control hemodynamic changes induced by tracheal intubation using the transillumination method during total IV anesthesia. We therefore conducted this study to determine the effect-site concentration of remifentanil blunting hemodynamic responses after tracheal intubation in patients receiving propofol anesthesia.

Methods: We enrolled 26 healthy adult patients (ASA physical status I-II), aged 16-67 scheduled for surgery within 2 hours. All patients received a target-controlled infusion of $4 \mu \mathrm{g} / \mathrm{ml}$ propofol. The effect-site target-concentration of remifentanil of $5.0 \mathrm{ng} / \mathrm{ml}$ was chosen for the first patient. We used the Dixon's up-and-down sequential allocation method for determining the next remifentanil concentration. The time required for tracheal intubation was measured as the level of intubation stimulation.

Results: The average intubation time was $13.9 \pm 9.1$ seconds. From the Dixon's method, the $\mathrm{EC}_{50}$ of remifentanil blunting the hemodynamic response to tracheal intubation was $2.94 \mathrm{ng} / \mathrm{ml}$.

Conclusions: This study shows that effect-site concentrations of remifentanil of $2.94 \mathrm{ng} / \mathrm{ml}$ is effective in blunting sympathetic responses to tracheal intubation in $50 \%$ of patients with normal airway anatomy when combined with a target controlled infusion of propofol (4 $\mu \mathrm{g} / \mathrm{ml})$. (Korean J Anesthesiol 2011; 60: 398-402)

Key Words: Effect-site concentration, Light wand, Remifentanil, Tracheal intubation.

Received: April 16, 2010. Revised: 1st, May 11, 2010; 2nd, August 5, 2010. Accepted: December 9, 2010.

Corresponding author: Sangseok Lee, M.D., Department of Anesthesiology and Pain Medicine, Sanggye Paik Hospital, College of Medicine, Inje University, Sanggye 7-dong, Nowon-gu, Seoul 139-707, Korea. Tel: 82-2-950-1171, Fax: 82-2-950-1323, E-mail: sslee@paik.ac.kr

Euroanesthesia Annual Meeting, 2008, Copenhagen.

This work was supported by the Indang research grant of Inje University 2008.

(ㄷ) This is an open-access article distributed under the terms of the Creative Commons Attribution Non-Commercial License (http:// creativecommons.org/licenses/by-nc/3.0/), which permits unrestricted non-commercial use, distribution, and reproduction in any medium, provided the original work is properly cited. 


\section{Introduction}

Tracheal intubation commonly results in sympathetic stimulation manifested by hemodynamic change such as increased heart rate and arterial blood pressure. The strength of stimulation during laryngoscopic intubation is expressed as the product of its average force and duration [1]. Theoretically, use of the transillumination method for tracheal intubation may cause less adrenergic stimulation, because stimulation to epiglottis by laryngoscope is not required. However, many studies show that intubation with the transillumination method also increases blood pressure similar to direct laryngoscope $[2,3]$. Therefore, intubation with the transillumination method requires drugs for preventing hemodynamic changes due to sympathetic stimulation.

Remifentanil is a selective and strong opioid for the mureceptor. It has rapid onset, short duration, and context-sensitive time is 4 minutes. Therefore, it is widely used for endotracheal intubation to blunt hemodynamic response. This study is designed to find the effect-site concentration of remifentanil required for blunting hemodynamic responses after tracheal intubation with Surch-Lite ${ }^{\circledR}$ (Aron Medical, USA), accompanied by target-controlled infusion of $4 \mu \mathrm{g} / \mathrm{ml}$ of propofol.

\section{Materials and Methods}

After obtaining approval from our institutional review board and informed consent from each patient, we studied 26 ASA physical status I or II patients, between the ages of 16 and 65 , scheduled for surgery within 2 hours. Characteristics of the patients and intubation time are shown in Table 1 . There were 24 patients with Mallampati class I and 2 with class II. We excluded patients with Mallampati class III or IV, obese patients (body mass index $>30$ ). Patients with a history of previous difficult intubation or in whom a difficult intubation was suspected were also excluded. In addition, patients with a known abnormal airway, limited cervical spine movement and patients with current use of any cardiovascular medication were also excluded.

Table 1. Demographic Data for the Patients Enrolled in This Study

\begin{tabular}{lc}
\hline & Value \\
\hline Age (yr) & $30.3 \pm 1.1$ \\
Sex (M/F) & $12 / 14$ \\
Weight (Kg) & $60.2 \pm 2.8$ \\
Height (cm) & $166.7 \pm 7.8$ \\
Mallampati classification (I/II) & $24 / 2$ \\
Intubation time (sec) & $13.9 \pm 9.1$ \\
\hline
\end{tabular}

Age, weight, height and intubation time are expressed as mean \pm SD. Others are expressed as number of patients.
Thirty minutes before the induction of anesthesia, patients were premedicated with glycopyrrolate $0.2 \mathrm{mg}$ intramuscularly. After arrival in the operating room, non-invasive blood pressure, pulse oximetry and ECG were applied to patients. Ringer's lactate solution $(8-10 \mathrm{ml} / \mathrm{kg})$ was infused for replacement of deficit of the fast during 10-20 minutes. Systolic blood pressure, diastolic blood pressure, mean arterial pressure and heart rate as hemodynamic indicators were recorded at the following times: 1) before induction of anesthesia 2) before infusion of remifentanil 3) reaching target of effect site concentration of remifentanil 4) 1 minute before tracheal intubation 5) during tracheal intubation and 6) repeated by 1 minute interval up to 4 minutes after tracheal intubation. Upon arrival at the operating room, we assessed modified Mallampati classification (in the sitting position, tongue maximally forward on phonation) for each patient.

Induction of anesthesia was initiated with $100 \%$ oxygen $(5 \mathrm{~L} /$ min) under a facemask. After propofol and remifentanil were applied to the target-controlled infusion system (Base Primea Orchestra $^{\circledR}$, Fresenius Vial, France), Marsh model and Minto model were chosen for propofol and remifentanil, respectively. Target-controlled infusion modes were both effect-site concentration infusions. Initially, an effect site concentration of $4 \mu \mathrm{g} / \mathrm{ml}$ propofol was selected. At 1 minute after propofol infusion, remifentanil infusion was started. After loss of eyelash reflex, rocuronium of $0.6 \mathrm{mg} / \mathrm{kg}$ was administered intravenously. More than 3 minutes after rocuronium was administered and the target effect-site concentration was reached, tracheal intubation was performed with Surch-Lite ${ }^{\circledR}$. The first patient received an effect-site concentration of $5 \mathrm{ng} /$ $\mathrm{ml}$ remifentanil, then for decision of effect site concentration, Dixon's up-and-down method was used [4]. When a patient showed an increase of either heart rate or mean arterial blood pressure (MAP) $>20 \%$ immediately before the start of the remifentanil infusion value, the effect-site concentration of remifentanil given to the next patient was increased to $0.5 \mathrm{ng} /$ $\mathrm{ml}$ remifentanil (failed response). In the absence of either heart rate or MAP increasing $>20 \%$ immediately before the start of the remifentanil infusion value, the effect-site concentration given to the next patient was decreased to $0.5 \mathrm{ng} / \mathrm{ml}$ (successful response). Tracheal intubation for all patients was performed by a faculty member who had experience with more than 100 tracheal intubation procedures using Surch-Lite ${ }^{\circledR}$. We used 7.5-mm-ID endotracheal tubes for men and 7.0-mm-ID for female patients. The distal end of the light wand and covering lubricated tube was bent at a $90^{\circ}$ angle ("hockey stick"), and the patient's head and neck were placed in the neutral position. The jaw was lifted forward by the non-dominant hand of the anesthesiologist and the light wand and tube were inserted. The ambient light was dimmed to allow the visualization of 
transillumination. The cuff of the tracheal tube was inflated immediately after withdrawal of the light wand. The intubation time was also recorded, which was defined as the time required from jaw lifting to the removal of the device in the tracheal tube. If the heart rate of patients was less than 50 beat $/ \mathrm{min}$, $0.5 \mathrm{mg}$ atropine was administered intravenously. If mean arterial pressure was less than $50 \mathrm{mmHg}, 5 \mathrm{mg}$ ephedrine was administered intravenously.

Data was expressed as mean \pm SD. Statistical analysis was performed with the S-PLUS 8.0 (TIBCO Software Inc, CA, USA). We calculated $\mathrm{EC}_{50}$ of remifentanil blunting the hemodynamic response to tracheal intubation with derived data by Dixon's up-and-down method [4]. Statistical significance was declared if $\mathrm{P}<0.05$.

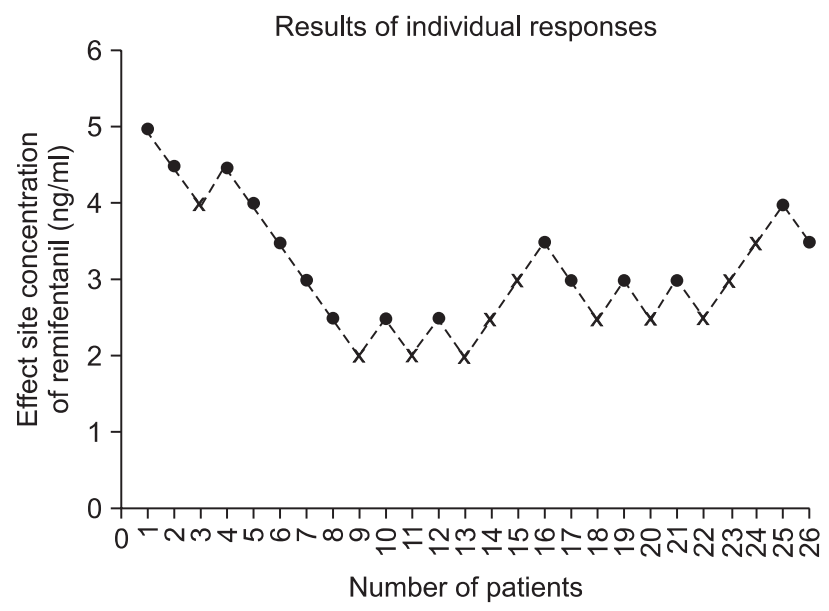

Fig. 1. Individual responses to tracheal intubation according to the upand-down sequence in patients receiving target-controlled effectsite concentration of remifentanil. The effect-site concentration of propofol was maintained at $4 \mu \mathrm{g} / \mathrm{ml}$ for all patients. If a patient showed any increase of either heart rate or mean arterial blood pressure (MAP) $>20 \%$ immediately before the start of the remifentanil infusion, the effect-site concentration of remifentanil given to the next patient was increased to $0.5 \mathrm{ng} / \mathrm{ml}$ of remifentanil (fail response; black cross mark). In the absence of either heart rate or MAP increasing $>20 \%$ immediately before the start of the remifentanil infusion, the effect-site concentration given to the next patient was decreased to $0.5 \mathrm{ng} / \mathrm{ml}$ (success response; black filled circle).

\section{Results}

Twenty-six patients were enrolled in the study. There were 24 patients with Mallampati class I and 2 with class II. Tracheal intubations were successful for the first trial in all patients. The average intubation time was $13.9 \pm 9.1$ seconds. In this study, ephedrine or atropine was not administered in any case. Individual responses to tracheal intubation according to the up-and-down sequence in patients receiving target-controlled effect-site concentration of remifentanil are shown in Fig. 1. The changes of hemodynamic responses (e.g. mean arterial pressure and heart rate) to endotracheal intubation are shown in Table 2.

After induction of anesthesia with $4 \mu \mathrm{g} / \mathrm{ml}$ of propofol concentration, we calculated the $\mathrm{EC}_{50}$ of remifentanil for blunting hemodynamic response to tracheal intubation with Surch-Lite ${ }^{\circledR}$ by Dixon's equation from his original papers [4]. In our study, $\mathrm{N}$ is more than 6 , thus $\mathrm{EC}_{50}$ estimate can be calculated by a factor which is dependent on the constant $A$ and $\mathrm{C}$ on tables from original Dixon's paper [4]. The estimate is as below:

$$
\frac{\sum X i}{N}+\frac{d}{N}(A+C)
$$

Where $N$ is total number of patients, $d$ is difference between dose levels ( $0.5 \mathrm{ng} / \mathrm{ml}$ ), $X i$ are the test levels (from $2.0 \mathrm{ng} / \mathrm{ml}$ to $5.0 \mathrm{ng} / \mathrm{ml}$ ) and $A$ and $C$ are obtained from the original paper [4]. Therefore, the mean $\mathrm{EC}_{50}$ of remifentanil blunting the hemodynamic response to tracheal intubation with Surch-Lite ${ }^{\circledR}$ was $2.94 \mathrm{ng} / \mathrm{ml}$.

\section{Discussion}

This study shows $\mathrm{EC}_{50}$ of the effect-site concentration of remifentanil to blunt hemodynamic change induced by tracheal intubation with Surch-Lite ${ }^{\circledR}$ was $2.94 \mathrm{ng} / \mathrm{ml}$ after induction of anesthesia using propofol of $4 \mu \mathrm{g} / \mathrm{ml}$. Tracheal intubation is associated with transient increases in systemic blood pressure and heart rate due to sympathetic stimulation. According to

Table 2. The Change of Hemodynamic Variables During the Study

\begin{tabular}{lcc}
\hline \multicolumn{1}{c}{ Recording time points } & MAP (mmHg) & HR (beats/min) \\
\hline Before induction of anesthesia & $89.7 \pm 9.9$ & $79.0 \pm 17.0$ \\
Before starting remifentanil infusion & $86.5 \pm 11.7$ & $80.7 \pm 15.5$ \\
On achieving the remifentanil targeted concentration & $77.8 \pm 8.8$ & $70.8 \pm 12.2$ \\
Immediately after tracheal intubation & $74.5 \pm 9.3$ & $72.9 \pm 14.5$ \\
1 minute after tracheal intubation & $87.4 \pm 14.3$ & $90.1 \pm 15.8$ \\
2 minute after tracheal intubation & $80.4 \pm 11.6$ & $85.0 \pm 17.1$ \\
3 minute after tracheal intubation & $73.0 \pm 9.7$ & $79.7 \pm 11.4$ \\
4 minute after tracheal intubation & $74.1 \pm 12.5$ & $80.8 \pm 13.3$
\end{tabular}

Data are expressed as mean \pm SD. MAP: mean arterial pressure, HR: heart rate. 
Hassan et al. [1], stimulation of proprioceptors at the base of the tongue during laryngoscope induces impulse-dependent increases in systemic blood pressure, heart rate and plasma catecholamine concentrations. The intensity of the stimulus exerted during laryngoscope is expressed by the product of its average force and duration.

Transillumination is an alternative method to direct laryngoscopic intubation for difficult intubations. However, the transillumination method also causes hemodynamic changes due to stimuli sympathetic tone when performing tracheal intubation [3]. We measured $\mathrm{EC}_{50}$ of effect-site concentration of remifentanil to blunt the hemodynamic change of tracheal intubation with Surch-Lite ${ }^{\circledR}$ during anesthesia with propofol and remifentanil.

Many studies have been conducted on the concentration of propofol required for appropriate unconsciousness when intravenous anesthesia was performed. Vuyk et al. [5] reported $\mathrm{EC}_{50}$ and $\mathrm{EC}_{95}$ effect-site concentration to induce unconsciousness in $50 \%$ and $95 \%$ of patients, were $3.4 \mu \mathrm{g} / \mathrm{ml}$ and $4.34 \mu \mathrm{g} / \mathrm{ml}$, respectively. Another study reported effect-site concentration of propofol for maintaining $41.1 \pm 2.5$ of bispectral index (BIS) was $3.5 \mu \mathrm{g} / \mathrm{ml}$ [6]. Based on these studies, we determined that the effect-site concentration of propofol was $4 \mu \mathrm{g} / \mathrm{ml}$ for gaining unconsciousness.

There have been many studies on the appropriate concentration of remifentanil to blunt hemodynamic change during tracheal intubation. Shin et al. [7] reported effect site concentrations of remifentanil to blunt sympathetic responses to tracheal intubation. In $50 \%$ and $95 \%$ of patients receiving a BIS-guided propofol anesthesia, the results were $1.37 \mathrm{ng} / \mathrm{ml}$ for men and $1.05 \mathrm{ng} / \mathrm{ml}$ for women. Lee et al. [8] reported effect site concentration of remifentanil to blunt hemodynamic change induced by tracheal intubation was $4 \mathrm{ng} / \mathrm{ml}$ and $6 \mathrm{ng} / \mathrm{ml}$ among groups of $0,2,4$ and $6 \mathrm{ng} / \mathrm{ml}$. In using laryngeal mask airway (LMA), $\mathrm{EC}_{50}$ of remifentanil needed inserting LMA was $3.18 \mathrm{ng} /$ $\mathrm{ml}$ in patients receiving effect site concentration of propofol of $4 \mu \mathrm{g} / \mathrm{ml}$ [9]. In our study, we set $5 \mathrm{ng} / \mathrm{ml}$ of remifentanil as the initial effect site concentration based on results of previous studies on blunting the hemodynamic response during tracheal intubation [10].

Lee et al. [11] reported effect-site concentration of remifentanil with Surch-Lite ${ }^{\circledR}$ in their study which was performed on 3 groups of 2, 4 and $6 \mathrm{ng} / \mathrm{ml}$, and the appropriate effect-site concentration was $4 \mathrm{ng} / \mathrm{ml}$. However, the drawback of their study was that the enrolled patients were divided into only 3 groups and the gap between each group was wide. It seems that sensitivity of their results was lower than our results. Another drawback was that they stopped infusing remifentanil before tracheal intubation. We think stopping infusion affect their results in the case of long intubation time. Differently to other studies [12,13], we measured intubation time as a level of intubation stimuli, because intubation time can influence hemodynamic change induced by tracheal intubation [14]. Intubation time in our study was $13.9 \pm 9.1$ seconds and it was not significantly different from other studies. In studies of Hwang et al. [12] and Lee et al. [13], intubation times were $11.8 \pm$ 6.6 seconds and $13 \pm 2$ seconds respectively and our intubation time was shorter than intubation time of Kohki et al. [15] of 30 seconds. Though we used appropriate propofol concentration based on other studies [5,6], we assessed loss of consciousness with eyelid reflex, not by using BIS. Objectivity about anesthetic depth was lower than other studies and it might affect our results. We used a noninvasive method for arterial blood pressure measurement such as that of Albertin et al. Though it did not show continuous results, we secured relatively correct result through short interval of measuring arterial blood pressure. If we had used systemic vascular resistance (SVR) and cardiac output or concentration of catecholamine as indicators of cardiovascular response, we could gain better results. Moreover, in this study we have selected only patients with normal airway anatomy. In the previous report of Wong et al., they showed that obesity (BMI $\geq 30 \mathrm{~kg} / \mathrm{m}^{2}$ ) and Mallampati class III/IV were major factors of difficulty of intubation using light wand [16]. Therefore, in clinical settings, it is possible that higher concentration of remifentanil would be required compared to our results, especially in patients with difficult airways.

In conclusion, the effect-site concentrations of remifentanil of $2.94 \mathrm{ng} / \mathrm{ml}$ is effective in blunting sympathetic responses to tracheal intubation with Surch-Lite ${ }^{\circledR}$ in $50 \%$ of patients with a normal airway anatomy when combined with a target controlled infusion of propofol $(4 \mu \mathrm{g} / \mathrm{ml})$.

\section{References}

1. Hassan HG, el-Sharkawy TY, Renck H, Mansour G, Fouda A. Hemodynamic and catecholamine responses to laryngoscopy with vs. without endotracheal intubation. Acta Anaesthesiol Scand 1991; 35: 442-7.

2. Knight RG, Castro T, Rastrelli AJ, Maschke S, Scavone JA. Arterial blood pressure and heart rate response to lighted stylet or direct laryngoscopy for endotracheal intubation. Anesthesiology 1988; 69: 269-72.

3. Yum KW, Oh YS, Oh SE. Comparative Study of Hemodynamic Changes and Complications following Lightwand of Laryngoscopic Intubation. Korean J Anesthesiol 1995; 28: 203-9.

4. Dixon WJ. The Up-And-Down Method For Small Samples. J Am Stat Assoc 1965; 60: 967-78.

5. Vuyk J, Engbers FH, Burm AG, Vletter AA, Griever GE, Olofsen E, et al. Pharmacodynamic interaction between propofol and alfentanil when given for induction of anesthesia. Anesthesiology 1996; 84: 288-99.

6. Kil HY, Lee SI, Lee SJ, Lee SW, Lee DH. The bispectral index and 
modified observer's assessment of alertness/sedation scale comparable to effect site concentration of propofol in Koreans. Korean J Anesthesiol 2000; 38: 251-7.

7. Shinn HK, Lee HS, Lee CS, Chung CK, Cha DC, Kim HH, et al. The Effect-Site Concentration of Remifentanil for Prevention of Increase of Blood Pressure and Heart Rate to Tracheal Intubation during Propofol-Remifentanil Total Intravenous Anesthesia in Korean. Korean J Anesthesiol 2006; 51: 312-7.

8. Lee JH, Kim SI, Ok SY, Kim SC. Evaluation of effect-site concentration of remifentanil for blunting hemodynamic responses to endotracheal intubation during total intravenous anesthesia using propofol. Korean J Anesthesiol 2007; 52: 269-74.

9. Kim JY, Park SY, Moon BK, Kim DW, Kim JS. Predicted effectsite concentration of remifentanil for facilitating laryngeal mask airway insertion with propofol target-controlled infusion. Korean J Anesthesiol 2007; 52: 381-5.

10. Albertin A, Casati A, Federica L, Roberto V, Travaglini V, Bergonzi $\mathrm{P}$, et al. The effect-site concentration of remifentanil blunting cardiovascular response to tracheal intubation and skin incision during bispectral index-guided propofol anesthesia. Anesth Analg 2005; 101: 125-30.

11. Lee JH, Jeon WJ, Shim JH, Cho SY, Yeom JH, Shin WJ, et al. What is an optimal effect site concentration of remifentanil for minimizing the hemodynamic change to endotracheal intubation using light wand?. Korean J Anesthesiol 2007; 52: 278-83.

12. Hwang JW, Noh GJ, Oh YS. Comparative study of light wand and direct laryngoscope: Correlation of time to intubation and thyromental distance, and change of blood pressure and heart rate after intubation. Korean J Anesthesiol 1999; 36; 949-54.

13. Lee HK, Yoo BH, Lee SS, Lim YH, Yon JH, Hong KH. Remifentanil effect-site concentration blunting cardiovascular responses to tracheal intubation for different sex during propofol infusion. Korean J Anesthesiol 2007; 52: 521-5.

14. Yoo BH, Lee S, Lee Y, Woo SH, Yon J, Hong K. The correlation between blood pressure elevation and intubation time during tracheal intubation using lightwand or direct laryngoscope. Korean J Anesthesiol 2007; 52: S9-13.

15. Nishikawa K, Omote K, Kawana S, Namiki A. A comparison of hemodynamic changes after endotracheal intubation by using the lightwand device and the laryngoscope in normotensive and hypertensive patients. Anesth Analg 2000; 90: 1203-7.

16. Wong SY, Coskunfirat ND, Hee HI, Li JY, Chen C, Tseng CH. Factors influencing time of intubation with a lightwand device in patients without known airway abnormality. J Clin Anesth 2004; 16: 326-31. 